\title{
PERBEDAAN RISIKO LINGKUNGAN PEKERJAAN DI KAWASAN HUTAN TERHADAP KEJADIAN MALARIA DIANTARA PASIEN PUSKESMAS BINUANG
}

\author{
Maharso, Noraida, Jumiatul Aulia \\ Poltekkes Kemenkes Banjarmasin Jurusan Kesehatan Lingkungan \\ Jl. H. Mistar Cokrokusumo No.1A Banjarbaru Kalimantan Selatan 70714 \\ E-mail: maharsom@gmail.com
}

\begin{abstract}
Environmental Risk Differences Occupations In Forest Areas Against Malaria Incidence Among Binuang Puskesmas Patient. Tapin district in South Kalimantan also has forest areas and is malaria endemic. Binuang District is an area with the most malaria cases. In 2012 clinical malaria was found in 364 cases with 197 positive cases. The objective of this research is to know the difference of work environment risk in the historic area against malaria incidence. The study material was the medical record of all patients at Binuang Public Health Center of Tapin District, in the first tier of year 2016. The results showed that not every exposure with vector habitat (forest area) acted as risk factor to malaria disease status. Through Chi Square test, it is not proven that the type of forest encroachment work is related to malaria incidence, $\mathrm{X}^{2}$ count value is 1.875 smaller than $\mathrm{X}^{2}$ table $(=3,841)$, is at the acceptance of $\mathrm{H}_{0}$. However, gold miners (in forest areas) have a risk of contracting malaria by 29.13 times greater than non-gold counterparts. The calculation result of $X^{2}$ is 41,76 bigger than $X^{2}$ table $(=3,841)$, reject $H_{0}$. For gold pending workers it is advisable to use insect repellent (repelent) and other mosquito-bitten protective gear while inside the gold repeating area.
\end{abstract}

Keywords: Malaria risk; Gold pending; Malaria forest area.

Abstrak: Perbedaan Risiko Lingkungan Pekerjaan Di Kawasan Hutan Terhadap Kejadian Malaria Diantara Pasien Puskesmas Binuang. Kabupaten Tapin di Kalimantan Selatan juga mempunyai kawasan hutan dan merupakan endemis malaria. Kecamatan Binuang merupakan daerah dengan kasus malaria terbanyak. Pada tahun 2012 ditemukan malaria klinis sebanyak 364 kasus dengan 197 kasus positif. Penelitian bertujuan untuk mengetahui perbedaan risiko lingkungan pekerjaan di kawasan hutaan terhadap kejadian malaria. Bahan penelitian adalah catatan medik dari seluruh pasien di Puskesmas Binuang Kabupaten Tapin, pada tribulan I tahun 2016. Hasil penelitian menunjukkan tidak setiap paparan dengan habitat vektor (kawasan hutan) berperan sebagai faktor risiko terhadap status sakit malaria. Melalui uji hubungan Chi Square tidak terbukti jenis pekerjaan perambah hutan berhubungan dengan kejadian malaria, nilai hitung $\mathrm{X}^{2}$ sebesar 1,875 lebih kecil dari $\mathrm{X}^{2}$ tabel $(=3,841)$, berada pada penerimaan $\mathrm{H}_{0}$. Akan tetapi pekerja pendulang emas (di kawasan hutan) mempunyai risiko tertular malaria sebesar 29,13 kali lebih besar dibanding pekerja bukan pendulang emas. Hasil perhitungan $\mathrm{X}^{2}$ sebesar 41,76 lebih besar dari $\mathrm{X}^{2}$ tabel $(=3,841)$, menolak $\mathrm{H}_{0}$. Bagi para pekerja pendulang emas disarankan menggunakan zat penolak serangga (repelent) dan alat pelindung gigitan nyamuk lainnya selama berada di dalam areal pendulangan emas.

Kata Kunci: Risiko malaria; pendulang emas; malaria kawasan hutan

\section{PENDAHULUAN}

Secara spesifik, Kementerian

Kesehatan menetapkan empat prioritas kesehatan dalam RPJMN, pada kurun waktu 2015-2017, yaitu : 1) menurunkan angka kematian ibu dan angka kematian bayi; 2) menurunkan prevalensi balita stunting; 3) menanggulangi penyakit menular HIV-AIDS, Tuberculosis, dan Malaria; dan 4) menanggulangi penyakit tidak menular Hipertensi, Diabetes, Obesitas, Kanker, dan gangguan jiwa [1].

Di Indonesia terdapat 15 juta kasus malaria setiap tahun dan 30.000 diantaranya meninggal dunia. Dari 293 kabupaten/kota di Indonesia, 167 
kabupaten/kota merupakan wilayah endemis malaria. Mengingat keberadaan habitat vektor malaria tidak sama rata antara daerah urban, sub urban, maupun daerah rural, maka dapat diperkirakan bahwa perbedaan paparan (karena perbedaan cluster, geografis, dan topografis) menyebabkan risiko tertular malaria juga menjadi berbeda pula. Diperkirakan 35\% penduduk Indonesia tinggal di daerah yang berisiko tertular malaria [2].

Kecamatan Binuang merupakan daerah dengan jumlah penderita terbanyak di Kabupaten Tapin, Provinsi Kalimantan Selatan. Pada tahun 2011 ditemukan kasus malaria klinis sebanyak 535 kasus dengan 332 kasus positif. Pada tahun 2012 ditemukan kasus malaria klinis sebanyak 364 kasus dengan 197 kasus positif [3].

\section{BAHAN DAN CARA PENELITIAN}

Bahan penelitian berasal dari catatan medik dari seluruh pasien yang terdaftar dalam catatan rekam medik Puskesmas Binuang Kabupaten Tapin, pada tribulan I tahun 2016. Kelompok kasus adalah seluruh penderita positif malaria yang terdaftar dalam catatan rekam medik Puskesmas Binuang. Sedangkan kelompok kontrol adalah seluruh pasien yang didiagosa selain malaria yang terdaftar dalam catatan rekam medik Puskesmas Binuang.

Jenis penelitian ini termasuk tipe observasional, karena tidak dilakukan manipulasi buatan pada faktor yang diteliti. Sedangkan sub tipe penelitian ini bersifat analitik, karena hasilnya dapat untuk merumuskan hipotesa tindakan yang dapat dilakukan untuk tindakan pencegahan potensial [4].

Pencuplikan sampel dilakukan secara purposive sampling, kelompok kontrol dipilih dari semua pasien yang didiagnosa malaria, yaitu sebanyak 16 orang, dan kelompok kontrol dipilih sebanyak 2 kali jumlah kasus (32 orang) dengan memilih subyek yang match dengan subyek kasus.

Data yang dikumpulkan kemudian ditabulasi silang, dengan menempatkan variabel risiko (jenis pekerjaan) disebebah kiri, dan variabel outcome (status kesakitan) disebelah kanan. Tabel deskriptif tersebut kemudian disederhanakan menjadi tabel silang antara tingkat keterpaparan faktor risiko dengan status kesakitan. Faktor risiko adalah perambah hutan, yaitu kelompok yang karena perkerjaan dituntut memasuki kawasan hutan (endemis malaria) setiap harinya; dan bukan perambah hutan, yaitu kelompok yang jenis pekerjaannya tidak mengharuskan memasuki kawasan hutan setiap harinya. Analisis dilanjutkan dengan menghitung risiko berdasarkan ukuran epidemiologi Odds dan Odds Ratio. Tidak dilakukan perhitungan ukuran Relative Risk (Risk Ratio), karena tidak tersedia data tentang Cummulative Incidence Rate kelompok terpapar faktor risiko maupun kelompok tidak terpapar faktor risiko [5]. Dengan demikian ukuran risiko hanya dilakukan pada probabilitas Odds, sebagai berikut: 1). Probabilitas (Odds) terserang malaria diantara para pekerja perambah hutan $[5,6], 2)$. Probabilitas (Odds) terserang malaria diantara pekerja bukan perambah hutan [5,6], 3). Odds Ratio (Relative Odds), yaitu Odds terserang malaria diantara perambah hutan dibandingkan Odds terserang malaria diantara bukan perambah hutan [5,6] dan 4). Dilakukan uji statistik dengan menggunakan rumus empiris Chi-Square untuk menguji ada tidaknya bukti secara statistik hubungan/asosiasi antara jenis pekerjaan perambah hutan dengan kejadian malaria [7].

\section{HASIL PENELITIAN DAN PEMBAHASAN}

\section{A. Keadaan Demografi}

Jumlah penduduk Kecamatan Binuang berdasarkan data Profil Kecamatan tahun 2014 adalah 27.940 jiwa. Dengan luas wilayah 218,10 Km2. Dengan perincian jumlah penduduk Lakilaki 14.117 jiwa dan penduduk perempuan 13.823 jiwa . Jumlah KK sebanyak $7.636 \mathrm{KK}$, dengan rata-rata 4 jiwa / KK , sedangkan kepadatan penduduknya adalah 228 / Km persegi 
Berdasarkan data yang dikumpulkan diketahui bahwa semua jenis kelamin responden adalah laki-laki dan umur responden yang termuda adalah 16 tahun dan responden tertua berumur 51 tahun dan diketahui bahwa keseluruhan responden pada kelompok kasus dan kelompok kontrol berada pada kelompok umur produktif, golongan umur responden adalah berkisar antara umur 15-54 tahun.

\section{B. Distribusi Responden Menurut Jenis Pekerjaan}

Pada tabel 1 distribusi kasus dan kontrol berikut ini, terlihat bahwa jenis pekerjaan terbanyak pada kelompok kasus adalah sebagai pendulang emas $87,5 \%$ dan pada kelompok kontrol adalah sebagai petani karet $21.875 \%$. Sedangkan kawasan lokasi pendulangan emas ternyata berada di kawasan hutan endemis malaria [8]. Dengan demikian nampak bahwa pasien Puskesmas Binuang yang didiagnosa malaria, sebagian besar mempunyai jenis pekerjaan di kawasan hutan endemis malaria. Meskipun tidak seluruh pekerja yang lingkungan kerjanya berada di kawasan hutan endemis malaria yang berobat ke Puskesmas Binuang, didiagnosa sebagai penderita malaria.

Tabel 1. Distribusi Kasus dan Kontrol Menurut Jenis Pekerjaan

\begin{tabular}{llcccc}
\hline \multirow{2}{*}{ No } & \multirow{2}{*}{ Jenis Pekerjaan } & \multicolumn{2}{c}{ Kasus } & \multicolumn{2}{c}{ Kontrol } \\
& & Responden & $\%$ & Responden & $\%$ \\
\hline 1 & Pegawai Pemerintah & 1 & 6,25 & 4 & 12,5 \\
2 & Pedagang & 0 & 0 & 2 & 6,25 \\
3 & Buruh Batubara & 0 & 0 & 5 & 15,625 \\
4 & Buruh Kelapa Sawit & 0 & 0 & 5 & 15,625 \\
5 & Petani Karet & 1 & 6,25 & 7 & 21.875 \\
6 & Petani Padi & 0 & 0 & 2 & 6,25 \\
7 & Pendulang Emas & 14 & 87,5 & 6 & 18,75 \\
8 & Buruh Bangunan & 0 & 0 & 1 & 3,125 \\
& Total & 16 & 100 & 32 & 100 \\
\hline
\end{tabular}

Pada tabel deskriptif diatas tampak bahwa kelompok kasus malaria didominasi oleh responden dengan jenis pekerjaan pendulang emas $(87,5 \%)$. Tabel tersebut juga mendeskripsikan bahwa pada kelompok kontrol kasus malaria yang mempunyai proporsi terbesar adalah dari kelompok dengan jenis pekerjaan petani karet $(21,88 \%)$ dan pendulang emas $(18,75 \%)$.

Tabel 1 diatas juga menjelaskan bbahwa tidak semua jenis pekerjaan yang bersinggungan dengan hutan di Kecamatan Binuang merupakan kawasan endemis malaria. Pada tabel tersebut ada beberapa jenis pekerjaan Responden yang berada di kawasan hutan sebagai habitat Anopheles konvensional, namun hanya lokasi tambang emaslah yang berada di kasawan hutan endemis malaria. Dengan demikian probabilitas para pekerja tambang emas untuk tertular malaria dapat dianalisis melalui tabel 2 berikut ini. 
Tabel 2. Probabilitas Kejadian Malaria Menurut Jenis Pekerjaan Pendulang Emas

\begin{tabular}{ccccccc}
\hline No. & \multicolumn{1}{c}{ Pekerjaan } & Kasus & Kontrol & Total & Odds & $\begin{array}{c}\text { OR } \\
\text { (Odds Ratio) }\end{array}$ \\
\hline 1. & Pendulang emas & 14 & 6 & 20 & 2,33 & 29,13 \\
2. & Bukan pendulang emas & $(70 \%)$ & $(30 \%)$ & $(100 \%)$ & & \\
& 2 & 26 & 28 & 0,08 & \\
& Jumlah & $(7,1 \%)$ & $(92,9 \%)$ & $(100 \%)$ & & \\
\hline
\end{tabular}

Tabel probabilitas kejadian malaria diatas mendeskripsikan pola kejadian sebagai berikut: 1). Probabilitas (Odds) terserang malaria diantara para pekerja pendulang emas sebesar 2,33 kali dibandingkan tidak terserang malaria, 2). Probabilitas (Odds) terserang malaria diantara pekerja bukan pendulang emas sebesar 0,08 kali dibanding tidak terserang malaria dan 3). Odds Ratio, yaitu Odds terserang malaria diantara pendulang emas adalah sebesar 29,13 kali dibandingkan Odds terserang malaria diantara bukan pendulang emas.

Pada kasus yang disajikan pada tabel.2 diatas tidak dapat ditentukan ukuran hubungan Relative Risk (Risk Ratio). Hal itu disebabkan untuk menghitung ukuran Relative Risk diperlukan data tentang seluruh insidens malaria (seluruh kasus baru) dan data individu dalam kelompok risiko seluruhnya (dalam suatu tempat dan waktu tertentu). Sedangkan pada tabel.2 diatas, banyaknya kasus ditentukan terlebih dahulu pada saat perencanaan menentukan besarnya sampel. Demikian halnya jumlah kontrol juga ditentukan pada tahap perencanaan, yang pada kajian ini ditentukan sebanyak 2 kali jumlah kasus. Oleh karena itu jumlah responden sebanyak 48 orang tidak sama dengan population at risk, dan nilai hubungan Relative Risk tidak pada tempatnya untuk dipaksakan dihitung.

Selanjutnya untuk menguji apakah fenomena probabilitas dan risiko terserang malaria yang dideskripsikan pada tabel 2 terjadi secara kebetulan atau memang berpola seperti itu, maka dilakukan pembuktian ada tidaknya bukti secara statistik hubungan/asosiasi antara jenis pekerjaan sebagai pendulang emas dengan kejadian malaria. Pengujian dilakukan dengan rumus empiris uji Chi Square (Fisher Exact) sebagai berikut.

Tabel 3. Tabel Kerja Uji Beda Chi Square Pendulang Emas

\begin{tabular}{ccccc}
\hline$O$ & $E$ & $0-E$ & $(O-E)^{2}$ & $(O-E)^{2} / O$ \\
\hline 14 & 6,67 & 7,33 & 53,78 & 3,84 \\
6 & 13,33 & $-7,33$ & 53,78 & 8,96 \\
2 & 9,33 & $-7,33$ & 53,78 & 26,89 \\
26 & 18,67 & 7,33 & 53,78 & 2,07 \\
& & & $X^{2}=$ & 41,76 \\
\hline
\end{tabular}




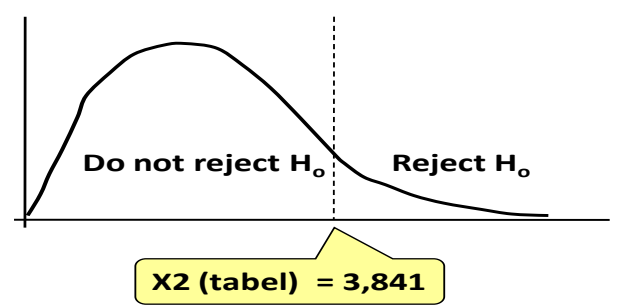

\begin{tabular}{|c|c|c|c|c|c|c|c|c|}
\hline \multirow{2}{*}{ df } & \multicolumn{7}{|c|}{$\boldsymbol{\alpha}$} \\
\cline { 2 - 9 } & $\mathbf{0 , 9 9}$ & $\mathbf{0 , 9 5}$ & $\mathbf{0 , 9 0}$ & $\mathbf{0 , 5 0}$ & $\mathbf{0 , 1 0}$ & $\mathbf{0 , 0 5}$ & $\mathbf{0 , 0 1}$ & $\mathbf{0 , 0 0 1}$ \\
\hline 1 & $\mathbf{0 0 1 5 7}$ & $\mathbf{, 0 0 3 9 3}$ & $\mathbf{, 0 1 5 8}$ & $\mathbf{, 4 5 5}$ & $\mathbf{2 , 7 0 6}$ & $\mathbf{3 , 8 4 1}$ & $\mathbf{6 , 6 3 5}$ & $\mathbf{1 0 , 8 2 7}$ \\
\hline 2 & $\mathbf{0 2 0 1}$ & $\mathbf{1 0 3}$ & $\mathbf{2 1 1}$ & $\mathbf{1 , 3 8 6}$ & $\mathbf{4 , 6 0 5}$ & $\mathbf{5 , 9 9 1}$ & $\mathbf{9 , 2 1 0}$ & $\mathbf{1 3 , 8 1 5}$ \\
\hline$\ldots$. & $\ldots$. & $\ldots$. & $\ldots$. & $\ldots$. & $\ldots$. & $\ldots$. & $\ldots$. & $\ldots$. \\
\hline dst & dst & dst & dst & dst & dst & dst & dst & dst \\
\hline
\end{tabular}

Gambar 1. Batas Penerimaan dan Penolakan Hipotesa

Hasil perhitungan X2 hitung ternyata menghasilkan nilai sebesar 41,76. Nilai ini lebih besar dibanding batas penolakan Ho untuk derajat kemaknaan $95 \%$ dan degree of freedom (df) = 1, yaitu 3,841. Dengan demikian cukup bukti secara statistik untuk menyatakan bahwa jenis pekerjaan penambang emas mempunyai risiko berbeda dengan bukan pendulang emas untuk menderita malaria. Dengan kata lain para pendulang emas di wilayah Puskesmas Binuang diyakini mempunyai risiko terserang (tertular) malaria sebesar 29,13 kali dibanding bukan penambang emas.

Fakta lapangan yang disajikan dalam tabel 1 memberikan informasi bahwa ada pula penderita malaria yang bekerja di kawasan hutan, atau setiap hari memasuki hutan dan berperilaku sebagai perambah hutan tetapi bukan pendulang emas. Probilitas kelompok ini untuk terserang malaria dianalisis melalui tabel berikut ini.

Tabel 4. Probabilitas Kejadian Malaria Menurut Jenis Pekerjaan Perambah Hutan

\begin{tabular}{ccccccc}
\hline No. & Pekerjaan & Kasus & Kontrol & Total & Odds & $\begin{array}{c}\text { OR } \\
\text { (Odds Ratio) }\end{array}$ \\
\hline 1. & Perambah hutan & 15 & 25 & 40 & 0,60 & 4,29 \\
\multirow{2}{*}{ 2. } & Bukan perambah hutan & $(37,5 \%)$ & $(62,5 \%)$ & $(100 \%)$ & & \\
& 1 & 7 & 8 & 0,14 & \\
& Jumlah & $(12,5 \%)$ & $(87,5 \%)$ & $(100 \%)$ & & \\
& 16 & 32 & 48 & & \\
\hline
\end{tabular}

Tabel probabilitas kejadian malaria diatas mendeskripsikan pola kejadian sebagai berikut: 1). Probabilitas (Odds) terserang malaria diantara para pekerja perambah hutan sebesar 0,6 kali dibandingkan tidak terserang malaria, 2). Probabilitas (Odds) terserang malaria diantara pekerja bukan perambah hutan sebesar 0,14 kali dibanding tidak terserang malaria dan 3). Odds Ratio, yaitu Odds terserang malaria diantara perambah hutan adalah sebesar 4,29 kali dibandingkan Odds terserang malaria diantara bukan perambah hutan.

Selanjutnya untuk menguji apakah fenomena probabilitas dan risiko terserang malaria yang dideskripsikan pada tabel 4 terjadi secara kebetulan atau memang berpola seperti itu, maka dilakukan pembuktian ulang seperti hubungan pekerjaan pendulang emas 
dengan kejadian malaria di wilayah kerja Puskesmas Binuang. Mengingat nilai exoected pada tabel tersebut yang mempunyai nilai kurang dari 5 sebesar 25\% ( $>20 \%$ ), maka digunakan rumus Yate's Correction dalam menentukan nilai X2 hitung.

Tabel 5. Tabel Kerja Uji Beda Chi Square Perambah Hutan

\begin{tabular}{ccccc}
\hline $\mathrm{O}$ & $\mathrm{E}$ & $0-\mathrm{E}$ & $(\mathrm{O}-\mathrm{E})^{2}$ & $(\mathrm{O}-\mathrm{E})^{2} / \mathrm{O}$ \\
\hline 15 & 13,3333333 & 1,66666667 & 2,777778 & 0,20833333 \\
25 & 26,6666667 & $-1,6666667$ & 2,777778 & 0,10416667 \\
1 & 2,66666667 & $-1,6666667$ & 2,777778 & 1,04166667 \\
7 & 5,33333333 & 1,66666667 & 2,777778 & 0,52083333 \\
\hline
\end{tabular}

Oleh karena ada nilai Expected yang $<5$ sebesar 25\%, maka dipergunakan rumus Yates Correction untuk menguji ada atau tidaknya hubungan antara jenis pekerjaan perambah hutan dengan kejadian malaria diantara pasien Puskesmas Binuang. Hasil perhitungan dengan X2 hitung ternyata menghasilkan nilai sebesar 1,875. Nilai ini lebih kecil dibanding batas penolakan Ho untuk derajat kemaknaan $95 \%$ dan degree of freedom $(\mathrm{df})=1$, yaitu 3,841. Dengan demikian cukup bukti secara statistik untuk menyatakan bahwa jenis pekerjaan perambah hutan tidak mempunyai risiko berbeda dengan bukan perambah hutan untuk menderita malaria. Dengan kata lain pola probabilitas dan risiko yang digambarkan pada tabel 4 . terjadi karena faktor kebetulan.

\section{KESIMPULAN DAN SARAN}

Berdasarkan analisis dan uji hubungan probabilitas kejadian malaria diatas, baik menurut jenis pekerjaan pendulang emas mupun menurut jenis pekerjaan perambah hutan dapat disimpulkan sebagai berikut : Cukup bukti secara statistik untuk menyatakan bahwa perbedaan derajat paparan faktor risiko malaria (jenis pekerjaan) menyebabkan perbedaan probabilitas status kesakitan malaria di antara pasien Puskesmas Binuang. Tidak cukup bukti secara statistik untuk menyatakan setiap paparan dengan habitat vektor (kawasan hutan) di wilayah kerja Puskesmas Binuang berperan sebagai faktor risiko terhadap status sakit malaria. Nilai hitung
X2 sebesar 1,875 lebih kecil dari X2 tabel $(=3,841)$ atau berada pada penerimaan H0. Probabilitas (Odds) risiko terserang malaria diantara para pekerja pendulang emas sebesar 2,33 kali dibandingkan tidak terserang malaria. Para pekerja penambang emas mempunyai risiko tertular malaria sebesar 29,13 kali lebih besar dibandingkan para pekerja bukan pendulang emas. Cukup bukti secara statistik dengan hasil perhitungan X2 menghasilkan nilai sebesar 41,76 atau lebih besar dari X2 tabel $(=3,841)$ atau menolak H0. Ukuran asosiasi Odds Ratio diperlukan untuk mengukur besarnya kekuatan hubungan, dan uji Fisher Exact diperlukan untuk membuktikan kemaknaan hubungan secara statistik. Bagi para pekerja pendulang emas disarankan untuk menggunakan zat penolak serangga (repelent) dan alat pelindung gigitan nyamuk lainnya selama berada di dalam areal pendulangan emas. Dapat dilakukan penelitian lebih lanjut tentang perbedaan dinamika para pekerja penambang emas dengan kelompok dengan jenis pekerjaan lainnya yang sama-sama masuk dan bekerja dikawasan hutan. Faktor-faktor yang diteliti antara lain mobilitas pekerja (lama tinggal dalam hutan), penggunaan repelent, dan penggunaan pelindung spesifik lainnya.

\section{KEPUSTAKAAN}

1. Kemenkes; RPJMN Bidang Kesehatan; 2015;

2. Sucipto, Cecep Dani; Manual Lengkap Malaria; 2015; Penerbit Gosyen Publishing, Yogyakarta 
3. Dinas Kesehatan Kabupaten Tapin; Profil Kesehatan Kabupaten Tapin; 2014; Pemerintah Kabupaten Tapin, Rantau

4. David G. Kleinbaum, Lawrence L. Kupper; ,Epidemiologic Research Principles And Quantitative Methods; 1982; Hal Morgenstern, Van Nostrand Reinhold Company; New York

5. John M.Last, A Dictionary of Epidemiology, 2nd Ed, 1988; Oxford University Press,
6. Leon Gordis;, Epidemiology; 1996; W.B.Saunders Company, Philadelphia, Pennsylvania,

7. Anwar Hidayat, Tutorial Rumus Chi Square Dan Metode Hitung, 2012; https://www.statistikian.com/2012/ 11/rumus-chi-square.html,

8. Jumiatul Aulia, Hubungan Pekerjaan Dengan Kejadian Malaria Pada Pasien Yang Didiagnosa Positif Malaria Di Puskesmas Binuang Kabupaten Tapin Triwulan I Tahun; 2016; Skripsi, Poltekkes Banjarmasin. 
474 Jurnal Kesehatan Lingkungan Vol. 14 No. 2, Juli 2017

Jurnal Kesehatan Lingkungan Vol. 14 No. 2, Juli 2017 